\title{
Effectiveness of a Commercial Lactic Acid Bacteria Intervention Applied to Inhibit Shiga Toxin-Producing Escherichia coli on Refrigerated Vacuum-Aged Beef
}

\author{
Katie R. Kirsch,, Tamra N. Tolen, ${ }^{2}$ Jessica C. Hudson, ${ }^{1}$ Alejandro Castillo, ${ }^{2}$ \\ Davey Griffin, ${ }^{3}$ and T. Matthew Taylor ${ }^{2}$ \\ ${ }^{1}$ Department of Nutrition and Food Science, Texas A\&M University, College Station, TX, USA \\ ${ }^{2}$ Department of Animal Science, Texas A\&M University, College Station, TX, USA \\ ${ }^{3}$ Department of Animal Science, Texas A\&M AgriLife Extension, College Station, TX, USA \\ Correspondence should be addressed to T. Matthew Taylor; matt_taylor@tamu.edu
}

Received 12 December 2016; Revised 17 March 2017; Accepted 3 May 2017; Published 23 May 2017

Academic Editor: Marie Walsh

Copyright ( $\odot 2017$ Katie R. Kirsch et al. This is an open access article distributed under the Creative Commons Attribution License, which permits unrestricted use, distribution, and reproduction in any medium, provided the original work is properly cited.

Because of their antagonistic activity towards pathogenic and spoilage bacteria, some members of the lactic acid bacteria (LAB) have been evaluated for use as food biopreservatives. The objectives of this study were to assess the antimicrobial utility of a commercial LAB intervention against O157 and non-O157 Shiga-toxigenic E. coli (STEC) on intact beef strip loins during refrigerated vacuum aging and determine intervention efficacy as a function of mode of intervention application. Prerigor strip loins were inoculated with a cocktail $\left(8.9 \pm 0.1 \log _{10} \mathrm{CFU} / \mathrm{ml}\right)$ of rifampicin-resistant $\left(100.0 \mu \mathrm{g} / \mathrm{ml} ; \mathrm{Rif}^{\mathrm{R}}\right) \mathrm{O} 157$ and non-O157 STEC. Inoculated loins were chilled to $\leq 4^{\circ} \mathrm{C}$ and treated with $8.7 \pm 0.1 \log _{10} \mathrm{CFU} / \mathrm{ml} \mathrm{LAB}$ intervention using either a pressurized tank air sprayer (conventional application) or air-assisted electrostatic sprayer (ESS). Surviving STEC were enumerated on tryptic soy agar supplemented with $100.0 \mu \mathrm{g} / \mathrm{ml}$ rifampicin (TSAR) to determine STEC inhibition as a function of intervention application method (conventional, ESS) and refrigerated aging period (14, 28 days). Intervention application reduced STEC by $0.4 \log _{10} \mathrm{CFU} / \mathrm{cm}^{2}(p<0.05)$, although application method did not impact STEC reductions $(p>0.05)$. Data indicate that the LAB biopreservative may assist beef safety protection when utilized within a multi-intervention beef harvest, fabrication, and aging process.

\section{Introduction}

An estimated 175,905 Shiga-toxigenic Escherichia coli (STEC) foodborne disease cases occur in the United States each year, with non-O157 STEC being reportedly the causative agents in $64.1 \%$ of cases [1]. The US Department of Agriculture Food Safety and Inspection Service (USDA-FSIS) declared raw nonintact beef, as well as intact beef intended to be processed into nonintact beef, adulterated if found positive for $E$. coli belonging to serogroups $\mathrm{O} 26, \mathrm{O} 45, \mathrm{O} 103$, O111, O121, O145, and/or O157 [2]. Cattle serve as a reservoir of STEC [3-5]; eradication of these pathogens from the beef supply chain remains a challenge. Chemical food safety interventions such as lactic acid, peroxyacetic acid, and chlorine are commonly applied to reduce and/or eliminate spoilage and pathogenic organisms from beef surfaces [6-8]. However, consumer demand for natural or minimally processed foods $[9,10]$ suggests a need for alternative beef safety interventions [11].

The lactic acid bacteria (LAB), as a type of biopreservative, are reported to be useful for preventing the growth of pathogenic microbes on meat products $[12,13]$ and are in some instances classified as generally recognized as safe (GRAS) for use in nonintact, whole muscle cuts or carcasses, and ready-to-eat meats $[14,15]$. These organisms antagonize other bacteria, including human pathogens, through competition for nutrients and/or attachment sites, production of antimicrobial metabolites (e.g., reuterin, diacetyl, and fatty acids), bacteriocins (e.g., nisin, pediocin), and weak organic acids (e.g., lactic, acetic acid) $[16,17]$. Previous studies have explored the inhibitory mechanisms of specific protective 
TABLE 1: Shiga-toxigenic Escherichia coli isolate identification and sources.

\begin{tabular}{lcc}
\hline STEC serotype & Isolate ID $^{\mathrm{a}}$ & Source \\
\hline O104:H4 & TY-2482 ATCC BAA-178 & Human stool \\
O157:H7 & USDA-FSIS 380-94 & Salami isolate \\
O26:H11 & H30 & Infant with diarrhea \\
O103:H2 & CDC 90-3128 & Human stool \\
O45:H2 & CDC 96-3285 & Human stool \\
O145:NM & $83-75$ & Human stool \\
O111:H- & JB1-95 & Clinical isolate \\
O121:H19 & CDC 97-3068 & Human stool
\end{tabular}

${ }^{a}$ Isolates were provided by Luchansky, Ph.D. (USDA-Agricultural Research Service, Wyndmoor, PA).

cultures from members of the $\mathrm{LAB}$ for inhibition of $E$. coli O157:H7 in meats $[13,18-25]$. Nevertheless, to date little data are published detailing the antimicrobial efficacy of LAB food safety interventions for inhibiting members of the non-O157 STEC on fresh beef during storage and handling prior to retail. Therefore, the objectives of this study were to (i) assess the efficacy of a commercial LAB biopreservative (LactiGuard ${ }^{\mathrm{TM}}$, Guardian Food Technologies, LLC, Overland Park, KS) for the inhibition of eight STEC serogroups on beef subprimals during refrigerated vacuum aging and (ii) determine whether mode of intervention application (conventional spray, electrostatic spray [ESS]) impacts antimicrobial efficacy.

\section{Materials and Methods}

2.1. Bacterial Culture Maintenance. Rifampicin-resistant $\left(\right.$ Rif $^{\mathrm{R}}$ ) STEC strains encompassing O157 and the six O-groups of non-O157 STEC named as adulterants in raw nonintact beef [2], and E. coli O104:H4 (2011 European sprout outbreak) (STEC8), were provided by J. B. Luchansky, Ph.D. (US Department of Agriculture-Agricultural Research Service, Wyndmoor, PA, USA) (Table 1). Culture revival and maintenance procedures were completed according to previous methods [26]. Working cultures of isolates were prepared by transferring a loopful of culture from tryptic soy agar (TSA; Becton, Dickinson and Co., Sparks, MD, USA) slants into $10 \mathrm{ml}$ sterile tryptic soy broth (TSB) and incubating statically at $35^{\circ} \mathrm{C}$ for $18-24 \mathrm{~h}$. Each isolate was individually subcultured by inoculating a $50 \mathrm{ml}$ volume of sterile TSB supplemented with $0.1 \%(\mathrm{w} / \mathrm{v})$ rifampicin (Sigma-Aldrich, St. Louis, MO, USA) with one loopful of fresh culture and incubating statically at $35^{\circ} \mathrm{C}$ for $18-24 \mathrm{~h}$. Immediately prior to use, a cocktail of STEC isolates was prepared by transferring $50 \mathrm{ml}$ of each culture into a calibrated misting bottle (previously sanitized by immersion in $70 \%$ ethanol for $5 \mathrm{~min}$ followed by triplicate flushing with sterile distilled water). The targeted STEC concentration in the inoculum was $9.0 \log _{10} \mathrm{CFU} / \mathrm{ml}$ and was determined by serially diluting in $0.1 \%$ peptone water (Becton, Dickinson and Co.) and spreading on TSA supplemented with $100 \mu \mathrm{g} / \mathrm{ml}$ rifampicin (TSAR). Colonies were enumerated following incubation at $35^{\circ} \mathrm{C}$ for $18-24 \mathrm{~h}$. Inoculum preparation procedures were completed to provide nondiffering counts of each of the eight $E$. coli isolates by mixing equivalent volumes into the inoculation bottle and thoroughly mixing isolates together prior to application. Isolates were prepared for inoculation according to methods previously published by Kirsch et al. [26], who reported that STEC isolates identical to those used in the current study were able to achieve non-statistically differing counts following $24 \mathrm{~h}$ incubation at $35^{\circ} \mathrm{C}$ in a nutritious medium. Rif ${ }^{\mathrm{R}}$ organisms used in the current study were previously compared to antibiotic-sensitive parents for tolerance to common food safety interventions including heating, lactic acid exposure, and high pressure, with no statistically significant differences in survivors between parents and mutants [27].

The commercial biopreservative LactiGuard consisted of lyophilized powders containing a manufacturer-described set of Lactobacillus, Lactococcus, and Pediococcus spp. Immediately prior to use, a LactiGuard suspension was prepared by combining $7.5 \mathrm{~g}\left(11.0 \log _{10} \mathrm{CFU} / \mathrm{g}\right)$ of each organism (4 total) into 3.0 liters of sterile water to a concentration of $8.4 \log _{10} \mathrm{CFU} / \mathrm{ml}$. LAB numbers in the antimicrobial suspension prior to application to beef surfaces were verified by enumerating on de Man, Rogosa, and Sharpe (MRS) lactobacilli agar (Becton, Dickinson and Co.) supplemented with streptomycin sulfate $(40 \mu \mathrm{g} / \mathrm{ml}$, Amresco, Solon, $\mathrm{OH}$, USA), sodium oxacillin $(0.4 \mu \mathrm{g} / \mathrm{ml}$, Chem-Impex Int., Inc., Wood Dale, IL, USA), and gentamycin sulfate $(5 \mu \mathrm{g} / \mathrm{ml}$, Amresco), as per intervention supplier instructions. Colonies were enumerated following anaerobic incubation for $48 \mathrm{~h}$ at $35^{\circ} \mathrm{C}$.

2.2. Meat Preparation and Inoculation. Prerigor beef strip loins were procured from a federally inspected establishment in Texas and harvested within $2 \mathrm{~h}$ of animal death. Once collected, each strip loin was transferred into a polyethylene bag and swathed in a thermal blanket (EverReady First Aid, Brooklyn, NY, USA) to minimize heat loss. Beef pieces were then immediately transported in insulated coolers containing activated instant hot packs (Dynarex, Orangeburg, NY, USA) to a Texas A\&M AgriLife Research facility maintaining a BSL-2 Laboratory located within a $30 \mathrm{~min}$ drive of the beef slaughter establishment to inoculate strip loins as quickly as possible after collection (simulating prerigor carcass crosscontamination during beef harvest). At the facility, a prepared inoculum application spray bottle was primed and held 25 to $31 \mathrm{~cm}$ above the meat for application of three pumps of inoculum (1.0-1.5 $\mathrm{ml}$ per pump) onto the lean side of the strip loin surface. The bag containing the inoculated strip loin was closed with a zip tie and hand-tumbled for $1 \mathrm{~min}$ to distribute inoculum over beef surfaces. Beef pieces were held at $25^{\circ} \mathrm{C}$ for $30 \mathrm{~min}$ for inoculum attachment, loaded into a second polypropylene bag, and placed in insulated coolers containing frozen ice packs to initiate chilling. Coolers were transported to the Food Microbiology Laboratory (Texas A\&M University) within $8 \mathrm{~h}$ of inoculation and bacterial attachment. Upon return, bagged strip loins were removed from coolers and placed on shelves in a single layer in a $4^{\circ} \mathrm{C}$ walk-in cooler and held until a total chilling period of $24 \mathrm{~h}$ had elapsed. 
TABLE 2: Least squares means of bacterial populations on beef strip loins $\left(\log _{10} \mathrm{CFU} / \mathrm{cm}^{2}\right)$ treated with lab and vacuum aged at $4^{\circ} \mathrm{C}$.

\begin{tabular}{|c|c|c|c|c|c|c|}
\hline \multirow{2}{*}{ Target organisms } & \multicolumn{5}{|c|}{ Experimental process stage $^{a}$} & \multirow{2}{*}{$p$ value } \\
\hline & Postinoculation & Postchilling & Posttreatment & 14 days of aging & 28 days of aging & \\
\hline Control $^{\mathrm{b}}$ & $6.7 \mathrm{~A}$ & $6.6 \mathrm{~A}$ & - & $6.6 \mathrm{~A}$ & $6.3 \mathrm{~A}$ & 0.4047 \\
\hline STEC $^{c}$ & - & $7.2 \mathrm{~A}$ & $6.8 \mathrm{~B}$ & $7.1 \mathrm{AB}$ & $6.7 \mathrm{~B}$ & 0.0151 \\
\hline Lactic acid bacteria $\left(\mathrm{LAB}^{\mathrm{d}}\right)$ & - & - & $6.5 \mathrm{~A}$ & $6.2 \mathrm{~B}$ & $6.1 \mathrm{~B}$ & 0.0124 \\
\hline
\end{tabular}

${ }^{a}$ Values are least square means from two replications with triplicate samples in each replication $(n=6)$. Means within a row lacking the same capitalized letter (A, B) differ at $p=0.05$ by Tukey's Honestly Significant Differences (HSD) multiple comparisons test. ${ }^{b}$ Control indicates STEC counts from STEC-inoculated, nontreated beef strip loins. STEC were enumerated on tryptic soy agar supplemented with $100.0 \mu \mathrm{g} / \mathrm{ml}$ (TSAR) following $48 \mathrm{~h}$ incubation at $35^{\circ} \mathrm{C}$. ${ }^{\mathrm{c}} \mathrm{STEC}$ denotes STEC means from strip loins treated with the LAB intervention by pressurized spray or ESS. STEC were enumerated on tryptic soy agar supplemented with $100.0 \mu \mathrm{g} / \mathrm{ml}$ (TSAR) following $48 \mathrm{~h}$ incubation at $35^{\circ} \mathrm{C}$. Significant differences in STEC counts were not detected as a function of intervention application by pressurized spray versus ESS; counts of organisms are therefore compiled for both application methods; ${ }^{\mathrm{d}} \mathrm{LAB}$ denotes numbers of LAB enumerated from intervention-treated strip loins (pressurized spray, ESS). As significant differences in LAB counts were not detected as a function of intervention application by pressurized spray versus ESS, counts of organisms were compiled for both application methods. LAB from the biopreservative LactiGuard LAB were enumerated on de Man, Rogosa, and Sharpe (MRS) agar supplemented with streptomycin sulfate $(40 \mu \mathrm{g} / \mathrm{ml})$, sodium oxacillin $(0.4 \mu \mathrm{g} / \mathrm{ml})$, and gentamycin sulfate $(5 \mu \mathrm{g} / \mathrm{ml})$, as per manufacturer guidance.

2.3. Intervention Application to Beef. Following chilling, inoculated beef strip loins were readied for intervention application (under biosafety level 2 [BSL2] containment) and sample analysis. Prior to treatment application, a sterile meat hook was inserted into the distal end of the strip loin and strip loins were hung lean side facing outward in a model spray cabinet (Birko Corp., Centennial, CO, USA). Each piece was randomly assigned to a treatment: (a) conventionally spray-applied LactiGuard $\left[25^{\circ} \mathrm{C}\right.$ for $100 \mathrm{~s}$ at $310 \mathrm{kPa}, 1.7 \mathrm{ml} / \mathrm{min}$ flow rate]; (b) ESS-applied LactiGuard $\left[25^{\circ} \mathrm{C}\right.$ for $120 \mathrm{~s}$ at $207 \mathrm{kPa}$ ]; or (c) STEC-inoculated, untreated control. ESS application was performed using a XT-3 airassisted ESS sprayer (Electrostatic Spraying Solutions, Inc., Watkinsville, GA, USA) charged to $\leq-10$ amps at a flow rate of $2.1 \mathrm{ml} / \mathrm{s}$, while the conventional spray application was achieved using a hand-held, pressurized tank air sprayer (Roundup, Marysville, OH, USA) at a flow rate of $1.7 \mathrm{ml} / \mathrm{s}$. Interventions were sprayed approximately $90 \mathrm{~cm}$ from the strip loin surface in a sweeping horizontal zig-zag motion. Strip loins were then inserted into commercial-grade vacuum bags (oxygen transmission rate: $\leq 50 \mathrm{~cm}^{3} / \mathrm{m}^{2} \cdot 24 \mathrm{~h} \cdot 0.1 \mathrm{MPa}$; Weston, Strongville, OH, USA) and packaged in a vacuum sealer. Strip loins were arranged in a single layer and stored at $4^{\circ} \mathrm{C}$ for 14 or 28 days prior to postaging sampling.

2.4. Sampling and Microbiological Analysis. In order to track changes in meat $\mathrm{pH}$ as a function of intervention application, external $\mathrm{pH}$ of individual strip loins was measured in triplicate using an ExStik ${ }^{\circledR} \mathrm{pH}$ and temperature meter (Extech Instruments Corp., Nashua, NH, USA) before and after STEC inoculation, before and after LAB intervention treatment, and again after 14 and 28 days of refrigerated vacuum aging. For microbiological sampling, three $10 \mathrm{~cm}^{2}$ outlines were marked on the lean tissue surface using a flame-sterilized stainless steel borer, excised to a depth of 1-2 mm using flamesterilized scalpels and forceps, and composited into a sterile stomacher bag. Samples were then sealed and transported in insulated coolers packed with ice to the Food Microbiology Laboratory for analysis. Beef samples were assayed by adding $99 \mathrm{ml}$ phosphate buffered saline (PBS; Sigma-Aldrich Co.) to each sample pouch, pummeling for $1 \mathrm{~min}$ in a stomacher, serially diluting in $0.1 \%$ peptone water, and spreading on an appropriate medium. LactiGuard LAB were enumerated on MRS agar supplemented with antibiotics described above and incubated anaerobically $48 \mathrm{~h}$ at $35^{\circ} \mathrm{C}$ prior to colony counting. Rif $^{\mathrm{R}}$ STEC were spread on TSAR and colonies enumerated following incubation at $35^{\circ} \mathrm{C}$ for $24 \mathrm{~h}$.

2.5. Statistical Analysis. The experiment was completed via triplicate identical samples conducted over two replications $(N=6)$. All statistical analyses were performed using JMP Pro v11.0 (SAS Institute, Inc., Cary, NC, USA). Colony counts were transformed to $\log _{10} \mathrm{CFU} / \mathrm{cm}^{2}$; the limit of detection for the plating assays was $0.5 \log _{10} \mathrm{CFU} / \mathrm{cm}^{2}$. Differences between main effects (vacuum aging duration, and biopreservative intervention application method [control, conventional spray, ESS]) and their interaction were identified by analysis of variance (ANOVA) at a $p=0.05$. Statistical differences among means were separated with Tukey's Honestly Significant Differences (HSD) multiple comparisons test $(p<0.05)$.

\section{Results and Discussion}

To simulate cross-contamination during commercial animal slaughter prior to intervention application, beef strip loins were collected within $2 \mathrm{~h}$ of animal slaughter and inoculated as rapidly as possible. STEC inoculum fluid contained $8.9 \pm$ $0.1 \log _{10} \mathrm{CFU} / \mathrm{ml}$ prior to application to beef surfaces; STEC populations on inoculated strip loins remained unchanged during chilled transportation to the food microbiology laboratory prior to treatment (Table 2). Although control strip loins (STEC-inoculated, untreated) were handled identically to those subjected to LAB intervention treatment, STEC numbers enumerated from nontreated controls after chilling $\left(6.6 \pm 0.1 \log _{10} \mathrm{CFU} / \mathrm{cm}^{2}\right)$ were statistically lower than those from intervention-treated samples $\left(7.2 \pm 0.1 \log _{10} \mathrm{CFU} / \mathrm{cm}^{2}\right)$ $(p<0.05)$ (Table 2). This was unexpected; authors are uncertain as to the cause(s) behind this observed difference in STEC counts between controls and other samples eventually treated with LAB. 
Table 2 presents surviving populations of STEC and $\mathrm{LAB}$ on strip loins immediately following treatment during vacuum aging at $4^{\circ} \mathrm{C}$. Analysis of microbiological data determined method of intervention application (conventional spray, ESS) did not influence LAB numbers recovered from treated beef strip loins $\left(6.5 \pm 0.1 \log _{10} \mathrm{CFU} / \mathrm{cm}^{2}\right)$. Likewise, STEC numbers on treated strip loins did not differ as a function of the mode of LAB application method ( $p \geq 0.05)$. Nevertheless, STEC numbers on biopreservative-treated strip loins differed by intervention application with respect to STEC counts before and after treatment on strip loins and by posttreatment aging period ( $p=0.015$ ) (Table 2). Applying LAB onto beef strip loins resulted in a reduction in STEC of $0.4 \pm 0.1 \log _{10} \mathrm{CFU} / \mathrm{cm}^{2}(p<0.05)$. Once treated, subprimals were individually vacuum packaged and aged at $4^{\circ} \mathrm{C}$ for 14 or 28 days. On day 14 posttreatment, STEC numbers increased to $7.1 \log _{10} \mathrm{CFU} / \mathrm{cm}^{2}$ and were not different from STEC counts obtained immediately after intervention applications. Conversely, at 28 days of vacuum refrigerated aging, STEC counts $\left(6.7 \pm 0.1 \log _{10} \mathrm{CFU} / \mathrm{cm}^{2}\right)$ were significantly lower than pretreatment means $(p<0.05)$. At 14 days' vacuum refrigerated aging, $\mathrm{LAB}$ numbers on treated strip loin surfaces declined from posttreatment application counts to $6.2 \log _{10} \mathrm{CFU} / \mathrm{cm}^{2}$, though no further changes in $\mathrm{LAB}$ counts were detected at day 28 ( $p \geq 0.05$ ) (Table 2). Overall, reductions in STEC counts following intervention application and refrigerated aging were modest and not likely of great antimicrobial significance.

Outcomes from previous studies evaluating the antimicrobial activity of LAB biopreservatives against pathogens on beef products are mixed with respect to pathogen reduction results. Smith et al. [22] inoculated ground beef with $5.0 \log _{10} \mathrm{CFU} / \mathrm{g}$ of E. coli O157:H7 and 7.0 $\log _{10} \mathrm{CFU} / \mathrm{g}$ of LAB (Lactobacillus acidophilus strains NP 51, NP 25, NP 7 , and NP 3) and then stored the product at $5^{\circ} \mathrm{C}$ under vacuum for up to 5 days prior to analysis of pathogen survival. Compared to untreated controls, E. coli O157:H7 in treated beef was reduced by $>3.0 \log _{10} \mathrm{CFU} / \mathrm{g}$ following refrigeration for 5 days $(p<0.05)$. Echeverry et al. [28], conversely, reported that E. coli $\mathrm{O} 157: \mathrm{H} 7$ inoculated on refrigerated strip loins $\left(5.0 \log _{10} \mathrm{CFU} / \mathrm{cm}^{2}\right)$ treated with a spray consisting of $7.7 \log _{10} \mathrm{CFU} / \mathrm{ml} \mathrm{LAB}$ remained unchanged during refrigerated vacuum aging over 21 days, similar to findings reported herein. Finally, previous research has reported that reductions in E. coli $\mathrm{O} 157: \mathrm{H} 7$ on beef following treatment with $\mathrm{LAB}$ intervention were independent of LAB numbers applied, with no differences in E. coli O157:H7 numbers observed following incubation [29]. In the current study, numbers of LAB and STEC were nearly equivalent throughout the refrigerated aging period, yet LAB did not exert strong pathogen inhibition activity (Table 2 ). This may have resulted from insufficient levels of fermentable sugars for production of organic acids, lack of available oxygen for production of peroxides, or possibly other unanticipated factors. Finally, no effort to differentially count surviving STEC from intervention-treated or control strip loins during the experiment was attempted, disallowing authors from determining whether some members of the STEC inoculum were inhibited to greater or lesser extents than other inoculum members. While Kirsch et al. [26] reported differing morphological characteristics of STEC strains identical to those used herein on selective/differential media, it was noted that STEC isolates not bearing good isolation were frequently subject to misidentification on selective/differential plating medium surfaces. The enumeration of total surviving STEC from the inoculum would be expected to primarily yield counts of STEC isolates most tolerant to the antimicrobial intervention, though quantification of any differences in inhibition on individual STEC isolates was therefore precluded.

Mean surface $\mathrm{pH}$ of strip loins immediately prior to inoculation was $6.2 \pm 0.1$, while $\mathrm{pH}$ following meat inoculation and chilling of inoculated product declined to $5.8 \pm 0.1$ $(p<0.05)$ (data not shown). Whereas application of the LAB intervention by conventional pressurized sprayer versus ESS did not produce statistically significant differences in meat surface $\mathrm{pH}$, surface $\mathrm{pH}$ significantly decreased from the point of treatment application (LAB, control) to 14 days of refrigerated vacuum storage $(5.4 \pm 0.1)(p<0.05)$. A small, nonstatistically significant decline in meat surface $\mathrm{pH}$ was observed to occur between days 14 and 28 for refrigerated vacuum-aged strip loins $(5.3 \pm 0.1)(p>0.05)$ (data not shown). These $\mathrm{pH}$ declines mirror those for similarly chilled and vacuum-aged refrigerated beef in other studies where researchers determined LAB-driven declines in beef meat $\mathrm{pH}$ during chilled aging [30-32]. The inhibition of STEC by $\mathrm{LAB}$ is thought to result largely from production of organic acids [33]. However, exposure to sublethal stress (cold storage, carbohydrate limitation) may have limited acid fermentation output of $\operatorname{LAB}[34,35]$. Data indicate that acid fermentation of endogenous carbohydrate by applied LAB was insufficient to exert a greater degree of pathogen inhibition than that observed. This study investigated the efficacy of a commercial LAB food safety biopreservative intervention for inhibiting growth of eight $\mathrm{O} 157$ and nonO157 STEC isolates on beef strip loins during refrigerated vacuum aging. STEC numbers were reduced following treatment, and STEC populations on beef strip loins after 28 days of aging were lower than at pretreatment. However, pathogen reductions were small $\left(<1.0 \log _{10}\right.$-cycle). While not likely effective as a sole antimicrobial intervention for beef safety protection, biopreservative food safety interventions such as LactiGuard can be utilized to gain useful reductions in STEC when integrated into a multi-intervention process for beef safety protection during beef harvest and fresh beef products manufacture.

\section{Disclosure}

Katie R. Kirsch current affiliation is as follows: Department of Epidemiology and Biostatistics, Texas A\&M Health Science Center School of Public Health. The funding source did not have any role in the design of the experiment, experiment completion or data analysis, and manuscript preparation or submission. Guardian Food Technologies, LLC, did not have any role in experimental design, research completion, or manuscript preparation/submission. 


\section{Conflicts of Interest}

The authors declare that they have no conflicts of interest.

\section{Acknowledgments}

This material is based upon work that is supported by the National Institute of Food and Agriculture, US Department of Agriculture, Agriculture and Food Research Initiative Competitive Grants Program, under Award no. 2012-6800330155. Authors thank John Luchansky, Ph.D., US Department of Agriculture, Agricultural Research Service, for provision of STEC isolates. Authors express thanks to Forrest Mitchell, Ph.D., Department of Entomology, Texas A\&M AgriLife Research, for access to BSL-2 containment facilities to complete beef inoculation. Authors thank Gary Acuff, Ph.D., and the Texas A\&M Center for Food Safety for access to BSL-2 containment facilities to complete beef intervention application. LactiGuard was donated by Guardian Food Technologies, LLC (Overland Park, KS, USA). Authors thank Jason Sawyer, Ph.D., Tarleton State University, Stephenville, TX, for technical assistance provided.

\section{References}

[1] E. Scallan, R. M. Hoekstra, F. J. Angulo et al., "Foodborne illness acquired in the United States-major pathogens," Emerging Infectious Diseases, vol. 17, no. 1, pp. 7-15, 2011.

[2] USDA-FSIS, "Shiga toxin-producing Escherichia coliin certain raw beef products," Federal Register, vol. 76, pp. 58157-58165, 2011.

[3] J. Isiko, M. Khaitsa, and T. M. Bergholz, "Novel sequence types of non-O157 Shiga toxin-producing Escherichia coli isolated from cattle," Letters in Applied Microbiology, vol. 60, no. 6, pp. 552-557, 2015.

[4] H. S. Hussein, "Prevalence and pathogenicity of Shiga toxinproducing Escherichia coli in beef cattle and their products," Journal of Animal Science, vol. 85, no. 13, supplement, pp. E63E72, 2007.

[5] A. B. Ekiri, D. Landblom, D. Doetkott, S. Olet, W. L. Shelver, and M. L. Khaitsa, "Isolation and characterization of shiga toxinproducing Escherichia coli serogroups O26, O45, O103, O111, O113, O121, O145, and $\mathrm{O} 157$ shed from range and feedlot cattle from postweaning to slaughter," Journal of Food Protection, vol. 77, no. 7, pp. 1052-1061, 2014.

[6] J. H. Chen, Y. Ren, J. Seow, T. Liu, W. S. Bang, and H. G. Yuk, "Intervention technologies for ensuring microbiological safety of meat: current and future trends," Comprehensive Reviews in Food Science and Food Safety, vol. 11, no. 2, pp. 119-132, 2012.

[7] M. Koohmaraie, T. M. Arthur, J. M. Bosilevac, M. Guerini, S. D. Shackelford, and T. L. Wheeler, "Post-harvest interventions to reduce/eliminate pathogens in beef," Meat Science, vol. 71, no. 1, pp. 79-91, 2005.

[8] T. L. Wheeler, N. Kalchayanand, and J. M. Bosilevac, "Pre- and post-harvest interventions to reduce pathogen contamination in the U.S. beef industry," Meat Science, vol. 98, no. 3, pp. 372382, 2014

[9] A. E. J. McGill, “The potential effects of demands for natural and safe foods on global food security," Trends in Food Science and Technology, vol. 20, no. 9, pp. 402-406, 2009.
[10] M. Dickson-Spillmann, M. Siegrist, and C. Keller, "Attitudes toward chemicals are associated with preference for natural food," Food Quality and Preference, vol. 22, no. 1, pp. 149-156, 2011.

[11] M. Singh, S. M. Simpson, H. R. Mullins, and J. S. Dickson, "Thermal tolerance of acid-adapted and non-adapted Escherichia coli O157:H7 and Salmonella in ground beef during storage," Foodborne Pathogens and Disease, vol. 3, no. 4, pp. 439446, 2006.

[12] A. Amézquita and M. M. Brashears, "Competitive inhibition of Listeria monocytogenes in ready-to-eat meat products by lactic acid bacteria," Journal of Food Protection, vol. 65, no. 2, pp. 316325, 2002.

[13] A. Echeverry, J. C. Brooks, M. F. Miller, J. A. Collins, G. H. Loneragan, and M. M. Brashears, "Validation of lactic acid bacteria, lactic acid, and acidified sodium chlorite as decontaminating interventions to control Escherichia coli O157:H7 and Salmonella typhimurium DT 104 in mechanically tenderized and brine-enhanced (nonintact) beef at the purveyor," Journal of Food Protection, vol. 73, no. 12, pp. 2169-2179, 2010.

[14] FDA, "GRAS notification for the use of lactic acid bacteria to control pathogenic bacteria in meat and poultry products," 2012, https://www.fda.gov/downloads/Food/IngredientsPackagingLabeling/GRAS/NoticeInventory/ucm349355.pdf.

[15] USDA-FSIS, "Safe and suitable ingredients used in the production of meat, poultry, and egg products. Directive 7120.1, Rev. 40," 2017, http://www.fsis.usda.gov/wps/wcm/connect/bab10e09aefa-483b-8be8-809alf051d4c/7120.1.pdf?MOD=AJPERES.

[16] M. Ogawa, K. Shimizu, K. Nomoto et al., "Inhibition of in vitro growth of Shiga toxin-producing Escherichia coli O157:H7 by probiotic Lactobacillus strains due to production of lactic acid," International Journal of Food Microbiology, vol. 68, no. 1-2, pp. 135-140, 2001.

[17] L. Vold, A. Holck, Y. Wasteson, and H. Nissen, "High levels of background flora inhibits growth of Escherichia coli O157:H7 in ground beef," International Journal of Food Microbiology, vol. 56, no. 2-3, pp. 219-225, 2000.

[18] M. M. Brashears, S. S. Reilly, and S. E. Gilliland, "Antagonistic action of cells of Lactobacillus lactis toward Escherichia coli O157:H7 on refrigerated raw chicken meat," Journal of Food Protection, vol. 61, no. 2, pp. 166-170, 1998.

[19] S. Bredholt, T. Nesbakken, and A. Holck, "Protective cultures inhibit growth of Listeria monocytogenes and Escherichia coli O157:H7 in cooked, sliced, vacuum- and gas-packaged meat," International Journal of Food Microbiology, vol. 53, no. 1, pp. 4352, 1999.

[20] S. Chaillou, S. Christieans, M. Rivollier, I. Lucquin, M. C. Champomier-Vergès, and M. Zagorec, "Quantification and efficiency of Lactobacillus sakei strain mixtures used as protective cultures in ground beef," Meat Science, vol. 97, no. 3, pp. 332-338, 2014.

[21] J. R. Ruby and S. C. Ingham, "Evaluation of potential for inhibition of growth of Escherichia coli O157:H7 and multidrugresistant Salmonella serovars in raw beef by addition of a presumptive Lactobacillus sakei ground beef isolate," Journal of Food Protection, vol. 72, no. 2, pp. 251-259, 2009.

[22] L. Smith, J. E. Mann, K. Harris, M. F. Miller, and M. M. Brashears, "Reduction of Escherichia coli O157:H7 and Salmonella in ground beef using lactic acid bacteria and the impact on sensory properties," Journal of Food Protection, vol. 68, no. 8, pp. 15871592, 2005. 
[23] P. Muthukumarasamy, J. H. Han, and R. A. Holley, "Bactericidal effects of Lactobacillus reuteri and allyl isothiocyanate on Escherichia coli O157:H7 in refrigerated ground beef," Journal of Food Protection, vol. 66, no. 11, pp. 2038-2044, 2003.

[24] P. Muthukumarasamy and R. A. Holley, "Survival of Escherichia coli $\mathrm{O} 157: \mathrm{H7}$ in dry fermented sausages containing microencapsulated probiotic lactic acid bacteria," Food Microbiology, vol. 24, no. 1, pp. 82-88, 2007.

[25] S. Erkkilä, M. Venäläinen, S. Hielm, E. Petäjä, E. Puolanne, and T. Mattila-Sandholm, "Survival of Escherichia coli 0157:H7 in dry sausage fermented by probiotic lactic acid bacteria," Journal of the Science of Food and Agriculture, vol. 80, no. 14, pp. 21012104, 2000.

[26] K. R. Kirsch, T. M. Taylor, D. Griffin, A. Castillo, D. B. Marx, and L. Smith, "Growth of Shiga toxin-producing Escherichia coli (STEC) and impacts of chilling and post-inoculation storage on STEC attachment to beef surfaces," Food Microbiology, vol. 44, pp. 236-242, 2014.

[27] J. B. Luchansky, "Personal communication," 2017.

[28] A. Echeverry, J. C. Brooks, F. M. Markus, A. C. Jesse, H. L. Guy, and M. B. Mindy, "Validation of intervention strategies to control Escherichia coli O157:H7 and Salmonella typhimurium DT 104 in mechanically tenderized and brine-enhanced beef," Journal of Food Protection, vol. 72, no. 8, pp. 1616-1623, 2009.

[29] A. R. Hoyle, J. C. Brooks, L. D. Thompson, W. Palmore, T. P. Stephens, and M. M. Brashears, "Spoilage and safety characteristics of ground beef treated with lactic acid bacteria," Journal of Food Protection, vol. 72, no. 11, pp. 2278-2283, 2009.

[30] K. M. Wójciak and E. Solska, "Evolution of free amino acids, biogenic amines and $\mathrm{N}$-nitrosoamines throughout ageing in organic fermented beef," Acta Scientiarum Polonorum, Technologia Alimentaria, vol. 15, no. 2, pp. 191-200, 2016.

[31] R. Reid, S. Fanning, P. Whyte et al., "The microbiology of beef carcasses and primals during chilling and commercial storage," Food Microbiology, vol. 61, pp. 50-57, 2017.

[32] D. A. Mohrhauser, S. M. Lonergan, E. Huff-Lonergan, K. R. Underwood, and A. D. Weaver, "Calpain-1 activity in bovine muscle is primarily influenced by temperature, not $\mathrm{pH}$ decline," Journal of Animal Science, vol. 92, no. 3, pp. 1261-1270, 2014.

[33] M. M. Brashears and W. A. Durre, "Antagonistic action of Lactobacillus lactis toward Salmonella spp. and Escherichia coli O157:H7 during growth and refrigerated storage," Journal of Food Protection, vol. 62, no. 11, pp. 1336-1340, 1999.

[34] R. Cárcoba and A. Rodríguez, "Influence of cryoprotectants on the viability and acidifying activity of frozen and freeze-dried cells of the novel starter strain Lactococcus lactis ssp. lactis CECT 5180," European Food Research and Technology, vol. 211, no. 6, pp. 433-437, 2000.

[35] H. Velly, F. Fonseca, S. Passot, A. Delacroix-Buchet, and M. Bouix, "Cell growth and resistance of Lactococcus lactis subsp. lactis TOMSC161 following freezing, drying and freeze-dried storage are differentially affected by fermentation conditions," Journal of Applied Microbiology, vol. 117, no. 3, pp. 729-740, 2014. 

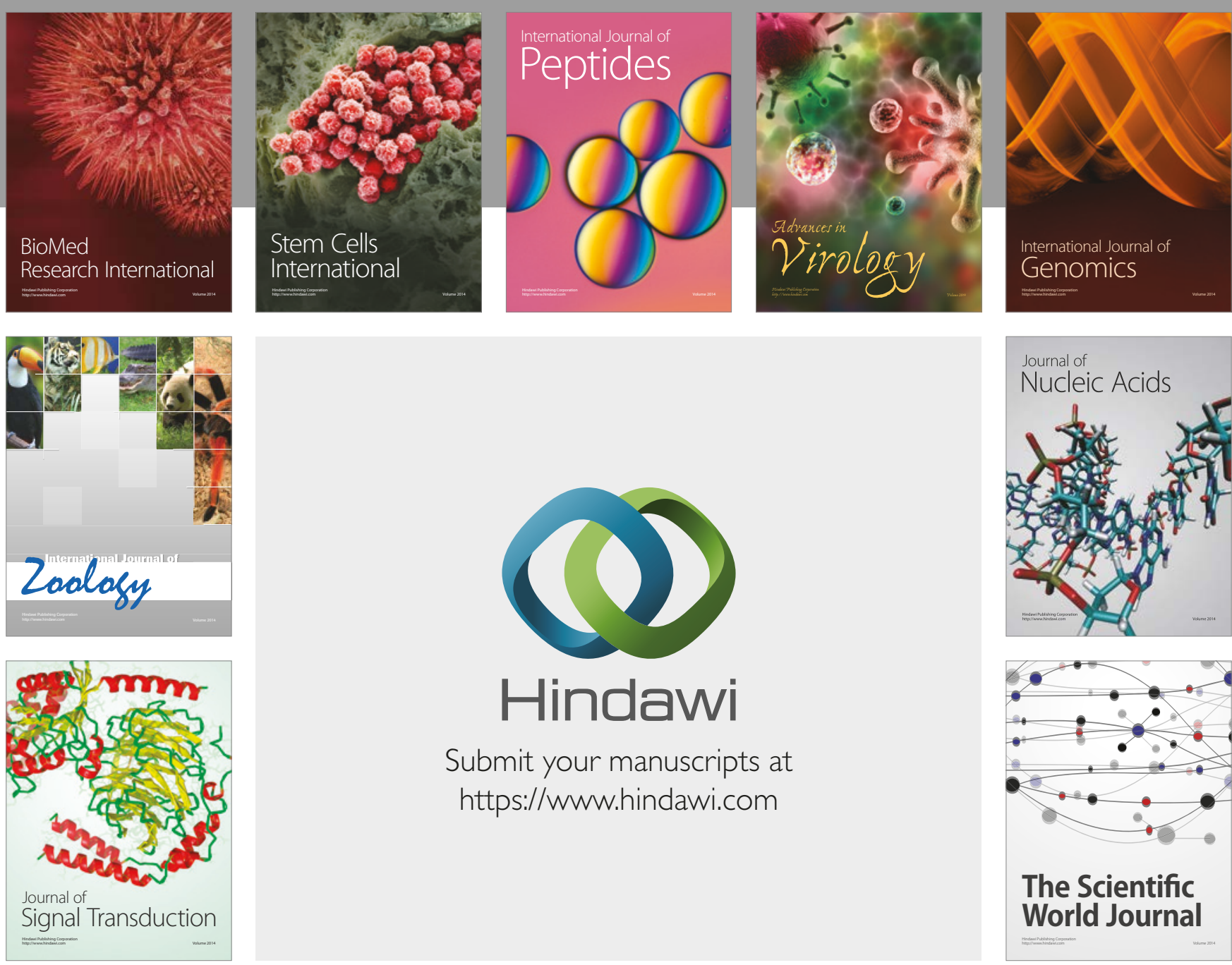

Submit your manuscripts at

https://www.hindawi.com
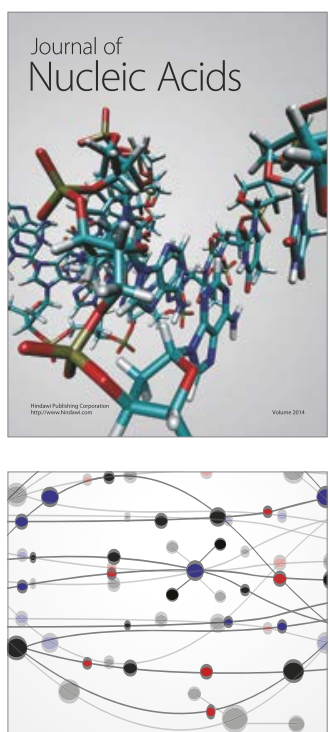

The Scientific World Journal

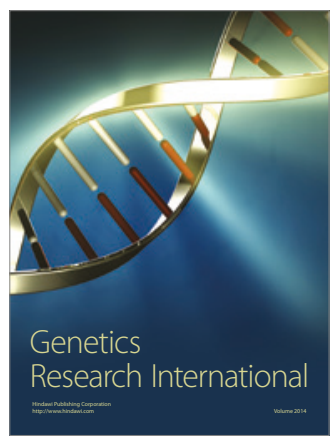

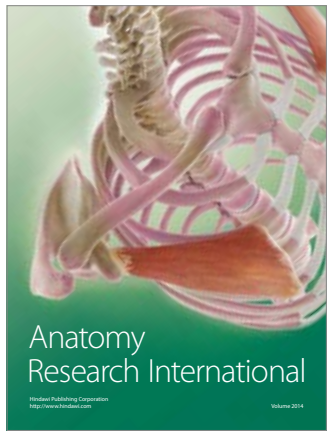

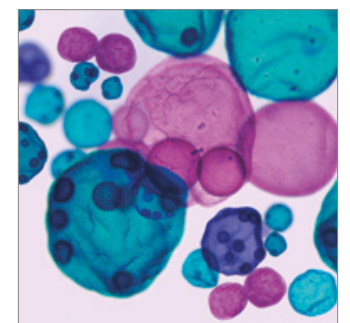

International Journal of Microbiology
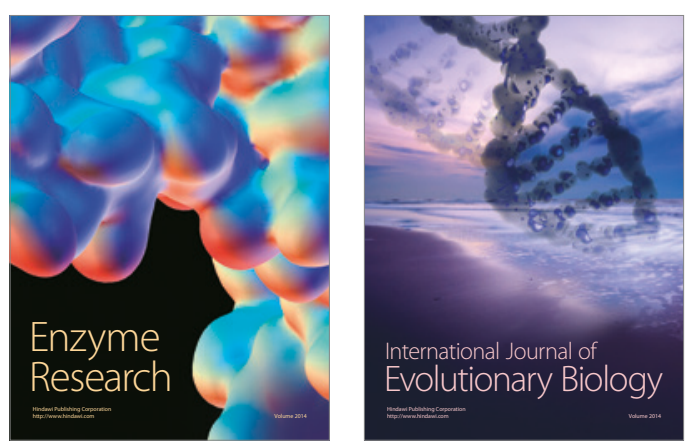


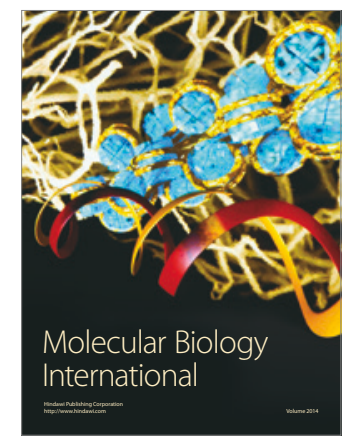

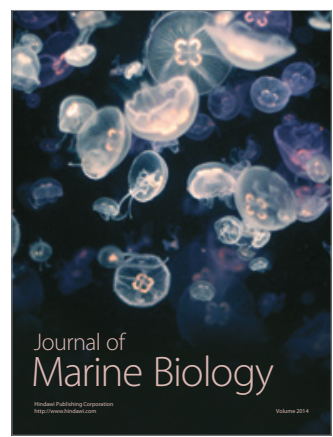

